\title{
Insights into Primate Dietary Ecology: Methods and Theory
}

\author{
Janine Chalk • Erin R. Vogel
}

Received: 6 April 2012 /Accepted: 17 April 2012 /Published online: 6 May 2012

(C) Springer Science+Business Media, LLC 2012

The theme of this special issue of the International Journal of Primatology centers on recent advances in primate feeding ecology methods. These articles represent lectures and the essence of demonstrations given during a two-day National Science Foundation-sponsored workshop hosted by the Center for Advanced Studies of Hominid Paleobiology and the Department of Anthropology at the George Washington University. In organizing this workshop and special issue, our aim was to bring together not only researchers using novel methods, but also those employing familiar methods in new ways to address a broad array of topics in primate feeding ecology. This workshop was modeled after a three-day workshop held in 1982 by the Primate Society of Great Britain and the Anatomical Society of Great Brittan and Ireland, which resulted in the classic volume Food Acquisition and Processing in Primates (Chivers et al. 1984). The series of articles presented here echo the breadth of research topics explored in that volume and describe new and exciting methods that inform our understanding of primate adaptations related to diet.

Historically, primarily observational studies have dominated the field of primate feeding ecology. These long-term studies have laid the foundation for testing ecological and behavioral hypotheses regarding primate feeding. However, even when longterm observational data are available, answering questions concerning primate diet

\section{J. Chalk $(\bowtie)$}

Department of Evolutionary Anthropology, Duke University, Durham, NC 27708, USA

e-mail: janine.chalk@duke.edu

\section{J. Chalk}

Hominid Paleobiology Doctoral Program, The George Washington University, Washington, DC 20052, USA

\section{E. R. Vogel}

The Department of Anthropology and the Center for Human Evolutionary Studies, Rutgers University, New Brunswick, NJ 08901, USA

E. R. Vogel

Center for the Advanced Study of Hominid Paleobiology, The George Washington University, Washington, DC 20052, USA 
selection involves teasing apart complex relationships among ecological, social, morphological, developmental, and idiosyncratic variables. Although laboratory experiments allow researchers to control some of these variables to test specific hypotheses, if these experiments do not replicate behaviors or decisions made in the wild they provide little relevant information (Bock and von Wahlert 1965; Janson 2012). As a result, over the past few decades, primate feeding ecology has seen a growing number of studies aimed at better integrating field and laboratory methods, with researchers designing more naturalistic experiments in the laboratory (IriarteDiaz et al. 2011; Reed and Ross 2010; Ross et al. 2012; Thompson et al. 2011; Vinyard et al. 2011), or adapting laboratory methods for use in the wild (Lucas et al. 2012; Moritz and Dominy 2012; Rothman et al. 2012; Vinyard et al. 2008, 2012; Vogel et al. 2012; Williams et al. 2008). In this issue, we highlight some of the current research using these strategies to gain a better understanding of the factors influencing primate diet selection in the wild.

The issue begins with a contribution from Janson (2012) stemming from three decades of observing capuchin monkeys and performing ecological field experiments on a wild population. He discusses both the successes and challenges of navigating field experiments aimed at examining the foraging and feeding decisions of primates living in Iguazú National Park, Argentina. Here he argues for an approach that falls somewhere in the middle of purely experimental or observational methods, which he terms quasi-experiments. Janson (2012) maintains that experimental data collected in a natural context and analyzed with powerful statistical modeling methods offer researchers the best opportunity to disentangle the effects of the hypothesized causal variables on the behaviors observed.

The following three papers present research describing new methods that capitalize on technological advances to collect direct, noninvasive, physiological measures of diet and feeding. In their paper, Rothman and colleagues (2012) provide a thorough review of methods for collecting food samples for nutritional analysis in the field, determining the nutritional composition of primate foods. Importantly, they detail the caveats of assessing nutrient intake rates by primates in the field. They follow up these methodological issues with a detailed discussion of how nutritional studies can help us answer the unknowns in primate feeding decisions and the evolution of primate feeding adaptations. In a paper focusing on protein balance, Vogel and co-workers (2012) discuss two methods for examining urea concentration and nitrogen isotope signatures from urine samples collected from wild primates. They then examine these indicators of protein limitation in relation to the availability of preferred foods and protein intake. Together, these two articles highlight the importance of quantifying energy and protein intake to better understand the variation found in primates. In their paper, Moritz and Dominy (2012) implement a novel method, infrared thermography, to examine the temperature of the aye-aye's derived third digit relative to the other digits during locomotor, tap foraging, and food extraction behaviors. The authors found that this digit remains cooler than the other digits and only during tap foraging behaviors does it reach a temperature comparable to that of the others. These results provide strong evidence to suggest that this unique digit has a distinct vascular supply that prevents heat loss while the individual is not tap foraging.

Three contributions integrate mechanical, physiological, behavioral, kinematic, and ecological data to examine primate feeding. Lucas et al. (2012) update the field 
methods currently used by several researchers to measure the toughness of primate foods. In this article, the authors compare toughness measures for various food tissues collected from wire, scissor, and wedge tests. If the goal of the research is to document the range toughness of food items consumed by a primate species, discrepancies between testing modes are inconsequential. However, if the objective is to explore evolutionary questions, test type becomes more important. To address these differences in research scope, the authors offer recommendations for which test type to employ in the field.

Both Vinyard et al. (2012) and Ross et al. (2012) emphasize the need for integrative research to understand the factors influencing primate feeding systems. Vinyard and colleagues (2012) take a laboratory method used primarily on captive animals and bring it to the field to develop an "ecological physiology" of feeding in free-ranging primates. They use a portable electromyogram (EMG) system that uses telemetry to record jaw-muscle activity patterns in wild primates, enabling them to study the behavior, ecology, and physiology of primates feeding in their natural environment. Their preliminary data from wild primates using these novel techniques suggest that chewing may be more variable than anticipated based on results from laboratory studies. Further, they combine these EMG methods with food mechanical properties analysis to explore the relationship between jaw-muscle EMG activity and leaf toughness in wild howler monkeys. In this article, the authors succeed in demonstrating how the laboratory can be brought into the field to integrate the fields of food mechanics, anatomy, behavior, and ecology. The contribution from Ross and co-workers (2012) reviews our current knowledge of the impact of food mechanical properties and feeding behavior on primate mandibular morphology. They highlight the need for additional data on how feeding behavior variables mediate the effects of food mechanical properties on morphology. They then provide a detailed example of their work synthesizing experimental and comparative methods to explore the impact of food mechanical properties on jaw kinematics variation.

The issue concludes with four articles discussing feeding ecology methods applicable to fossil primates. Constantino et al. (2012) describe a set of equations derived from materials science used to gauge maximum bite force in extant or extinct species. With this method, the authors analyze antemortem chips found in an expanded great ape sample. Although teeth of Pongo are the most frequently chipped, Gorilla was found to have the highest estimated maximum bite force of the three genera. The article concludes with an interesting discussion of the impact of potential complicating factors, including tooth wear and enamel thickness, on the equations' accuracy and highlights the future research required to validate the equations for additional taxa.

Crowley (2012) provides a thorough guide to understanding stable isotope techniques, methods for collecting and preparing samples, and how these techniques can be applied to answering questions regarding primate feeding ecology. Crowley (2012) discusses several applications of this analysis, followed by methods that detail how to carry them out. She ends with a section on how to analyze and interpret data collected using these methods. This is an invaluable and succinct guide for anyone interesting is applying stable isotope methods to dietary ecology in primates. In her contribution, Henry (2012) details an exciting application of studying plant microremains to reconstruct the diets of extinct species of primates, using references from living 
primates. Although very little research has been conducted using plant microremains to reconstruct the diets in fossil primates, she indicates how these methods have been used in the study of early hominin diets and how they can equally be applied to extinct, subfossil, and fossil primate species. These methods have the potential to deepen our understanding of early primate diets beyond what we can determine from traditional studies that examine craniodental traits in extinct species.

The final contribution is a unique review article from Wood and Schroer (2012). Here the authors use Paranthropus boisei as a case study to evaluate the efficacy of feeding ecology methods validated in living species to reconstruct fossil primate diets. They address the benefits and drawbacks of several reconstruction methods, including traditional methods such as comparative masticatory morphology function and stable isotopes, as well as relatively new methods such as dental topographic analysis and finite element modeling.

The utility of issues such as this is to make new methods in the field available to broad audience. Not all of the methods presented here will be appropriate for every species. However, we hope readers will be inspired to apply some of these methods to their own research questions to inform our understanding of primate feeding decisions and behavior.

Acknowledgments We thank our co-organizer Dr. Peter Lucas as well as all the invited speakers and guests who participated in the Innovative Methods in Feeding Ecology workshop at the George Washington University in March 2010 and contributed to this issue. We also extend our special thanks to Dr. Joanna Setchell for her support of this special issue of the International Journal of Primatology. In addition, we are grateful to the graduate students in the Hominid Paleobiology Doctoral Program for organizing and providing logistical support during the workshop and to Dennis Galvez for his editorial assistance while assembling the issue. Finally, we thank all of the referees for devoting time to review and improve these articles. This workshop was funded by the National Science Foundation IGERT grant DGE-0801634.

\section{References}

Bock, W. J., \& von Wahlert, G. (1965). Adaptation and the form-function complex. Evolution, 19(3), $269-299$.

Chivers, D. J., Wood, B. A., \& Bilsborough, A. (1984). Food acquisition and processing in primates. New York: Plenum.

Constantino, P. J., Markham, K., \& Lucas, P. W. (2012). Tooth chipping as a tool to reconstruct diets of great apes (Pongo, Gorilla, Pan). International Journal of Primatology, 33, doi:10.1007/s10764-0129595-2.

Crowley, B. E. (2012). Stable isotope techniques and applications for primatologists. International Journal of Primatology, 33, doi:10.1007/s10764-012-9582-7.

Henry, A. G. (2012). Recovering dietary information from extant and extinct primates using plant microremains. International Journal of Primatology, 33, doi:10.1007/s10764-011-9556-1.

Iriarte-Diaz, J., Reed, D. A., \& Ross, C. F. (2011). Sources of variance in temporal and spatial aspects of jaw kinematics in two species of primates feeding on foods of different properties. Integrative and Comparative Biology, 51(2), 307-319.

Janson, C. H. (2012). Reconciling rigor and range: Observations, experiments, and quasi-experiments in field primatology. International Journal of Primatology, 33, doi:10.1007/s10764-011-9550-7.

Lucas, P. W., Copes, L., Constantino, P. J., Vogel, E. R., Chalk, J., Talebi, M., et al. (2012). Measuring the toughness of primate foods and its ecological value. International Journal of Primatology, 33, doi:10.1007/s10764-011-9540-9.

Moritz, G. L., \& Dominy, N. J. (2012). Thermal imaging of aye-ayes (Daubentonia madagascariensis) reveals a dynamic vascular supply during haptic sensation. International Journal of Primatology, 33, doi:10.1007/s10764-011-9575-y. 
Reed, D. A., \& Ross, C. F. (2010). The influence of food material properties on jaw kinematics in the primate, Cebus. Archives of Oral Biology, 55, 946-962.

Ross, C. F., Iriarte-Diaz, J., \& Nunn, C. L. (2012). Innovative approaches to the relationship between diet and mandibular morphology in primates. International Journal of Primatology, 33.

Rothman, J. M., Chapman, C. A., \& van Soest, P. J. (2012). Methods in primate nutritional ecology: A user's guide. International Journal of Primatology, 33, doi:10.1007/s10764-011-9568-x.

Thompson, C. L., Donley, E. M., Stimpson, C. D., Horne, W. I., \& Vinyard, C. J. (2011). The influence of experimental manipulations on chewing speed during in vivo laboratory research in tufted capuchins (Cebus apella). American Journal of Physical Anthropology, 145(3), 402-414.

Vinyard, C. J., Glander, K. E., Teaford, M. F., Thompson, C. L., Deffenbaugh, M., \& Williams, S. H. (2012). Methods for studying the ecological physiology of feeding in free-ranging howlers (Alouatta palliata) at La Pacifica, Costa Rica. International Journal of Primatology, 33, doi:10.1007/s10764012-9579-2.

Vinyard, C. J., Taylor, A. B., Teaford, M. F., Glander, K. E., Ravosa, M. J., Rossie, J. B., Ryan, T. M., \& Williams, S. H. (2011). Are we looking for loads in all the right places? New research directions for studying the masticatory apparatus of New World monkeys. Anatomical Record-Advances in Integrative Anatomy and Evolutionary Biology, 294(12), 2140-2157.

Vinyard, C. J., Yamashita, N., \& Tan, C. (2008). Linking laboratory and field approaches in studying the evolutionary physiology of biting in bamboo lemurs. International Journal of Primatology, 29(6), 1421-1439.

Vogel, E. R., Crowley, B. E., Knott, C. D., Blakely, M. D., Larsen, M. D., \& Dominy, N. J. (2012). A noninvasive method for estimating nitrogen balance in free-ranging primates. International Journal of Primatology, 33, doi:10.1007/s10764-011-9543-6.

Williams, S. H., Vinyard, C. J., Glander, K. E., Deffenbaugh, M., Teaford, M. F., \& Thompson, C. L. (2008). Telemetry system for assessing jaw-muscle function in free-ranging primates. International Journal of Primatology, 29(6), 1441-1453.

Wood, B., \& Schroer, K. (2012). Reconstructing the diet and feeding of early hominins: The role of extant primate models. International Journal of Primatology, 33. 